\title{
Geografía y civilizaciones antiguas
}

\author{
Jean Pierre Bergoeing*
}

Recibido el 4 de febrero de 2014; aceptado el 1 de julio de 2014

\section{Summary}

The author makes references to the latest archeological discoveries associated with geomorphology wich allow to emit the hypothesis that the current civilization is much older that what is supposed.

Key words: climate change, Wurm, Riss, post-glaciar, transoceanic travels.

\section{Résumé}

L'auteur fait référence aux dernières découvertes archéologiques associées á la géomorphologie qui permettent d'émettre l'hypothèse que notre civilisation est beaucoup plus ancienne de ce que l'on peut supposer.

Mots clés: changements climatiques, Würm, Riss, post-glaciaire, voyages transocéaniques.

\section{Resumo}

$\mathrm{O}$ autor faz referências às recentes descobertas arqueológicas associadas à geomorfologia que permitem a emissão na hipótese de que a civilização moderna é muito mais antiga do que se supõe.

Palavras-chave: mudanças do clima, Wurm, Riss, pos glacial, viagem oceánica.

\section{Resumen}

El autor hace referencias a los últimos descubrimientos arquelógicos asociados a la geomorfología que permiten emitir la hipótesis que la civilización actual es mucho más antigua que lo que se supone.

Palabras clave: cambios climáticos, Wurm, Riss, posglaciar, viajes transoceánicos.

* Profesor catedrático, investigador, Universidad de Costa Rica, correo electrónico: jegadana@gmail.com 


\section{Introducción}

Las investigaciones recientes en diversos campos como la arqueología, la geomorfología, la geología, la palinología, la etnología, etc., son tantas ramas de una sola ciencia que podemos calificar como Ciencias de la Tierra. Ellas han permitido vislumbrar el pasado de la humanidad que sería mucho más antiguo de lo que hasta ahora se pensaba y en contradicción con los pensamientos clásicos que creían que nuestra civilización es el producto de una evolución que comenzó con el homo sapiens hace unos 200,000 a 140,000 años en África y a partir de entonces se habría diseminado por el mundo. Con el fin de la última glaciación hace unos 12,000 años habían llegado a América. Trataremos de explicar esto dentro de un concepto geográfico.

\section{Los cambios climáticos durante las últimas glaciaciones}

Durante el Cuaternario, la Tierra sufrió seis grandes glaciaciones, es decir, en los últimos dos millones de años. Sin embargo éste fenómeno se había producido anteriormente en la Tierra y se remonta a periodos como el Precámbrico y se ha reproducido hasta nuestra época. La Figura 1 muestra una datación de los periodos glaciares e interglaciares de los cuales se hace referencia.

El origen de los periodos glaciares e interglaciares fue explicado brillantemente por el geofísico serbio Milutin Milankovich (1879-1958), que los atribuye a tres fenómenos que sufre la Tierra: 1) excentricidad de su órbita alrededor del Sol en ciclos que varían cada 22,000 años; 2) inclinación axial de la Tierra cada 41,000 años que oscila entre $22.1^{\circ}$ y $24.5^{\circ}$ con respecto al plano de la eclíptica y 3 ) precesión o cambio en el bamboleo de sus polos cada 25,800 años, conocidos como ciclos de Milankovitch (Milankovitch, 1920).

A partir del esquema de las glaciaciones y periodos interglaciares podemos determinar que ellas condicionaron la evolución de civilizaciones humanas en el largo proceso evolutivo de la humanidad. Sin duda los periodos interglaciares como el actual comenzado hace 10,000 años, son aquellos donde la humanidad pudo desarrollarse con mayor facilidad, por las condiciones climáticas imperantes y que los periodos glaciares, fueron menos favorables por las mismas razones. Igualmente tenemos que tomar en consideración las variaciones del nivel marino que han tenido oscilaciones importantes con respecto al actual, alcanzando niveles de menos de 120 metros sobre el nivel actual durante la glaciación Wurm. Hace 6,500 años (optimum climático) por el contrario, la Tierra sufrió una subida del mar de cuatro metros conocida como transgresión Flandense; Jevreja et al. (2011), afirman que el nivel del mar ha subido de $2 \mathrm{~mm}$ /año durante el siglo XX y que seguirá subiendo hasta alcanzar 1.1 metros en 2100 y 5.5 metros en 2500 (Jevrejeva et al., 2011). Ello viene a demostrar cuán importante han sido las oscilaciones marinas en las migraciones intercontinentales. 


\begin{tabular}{llll}
\hline \multicolumn{1}{c}{ Clima } & \multicolumn{1}{c}{ Denominación } & Antigüedad & Época \\
\hline Posglacial & Actual & 10,000 & Holoceno \\
\hline Glacial & Glaciación de Würm o Wisconsin & 80,000 & \\
Interglaciar & Riss-Würm & 140,000 & \\
Glacial & Glaciación de Riss o Illinois & 200,000 & \\
Interglaciar & Mindel-Riss & 390,000 & \\
Glacial & Glaciación de Mindel o Kansas & 580,000 & Pleistoceno \\
Interglaciar & Gunz-Mindel & 750,000 & \\
Glacial & Glaciación de Gunz o Nebraska & $1.1 \mathrm{~m} . \mathrm{a}$. & \\
Interglaciar & Donau-Günz & $1.4 \mathrm{~m} . \mathrm{a}$. & \\
Glacial & Donau & $1.8 \mathrm{~m} . \mathrm{a}$. & \\
Interglaciar & Biber- Donau & $2 \mathrm{~m} . \mathrm{a}$. & \\
Glacial & Biber & $2.5 \mathrm{~m} . \mathrm{a}$. & \\
\hline Glacial & Oligoceno & $37 \mathrm{~m} . \mathrm{a}$. & Cenozoico \\
Interglaciar & Eoceno superior & $40 \mathrm{~m} . \mathrm{a}$. & \\
Glacial & Paleógeno & $80 \mathrm{~m} . \mathrm{a}$. & Mesozoico \\
\hline Interglaciar & Cretácico & $144 \mathrm{~m} . \mathrm{a}$. & Paleozoico \\
\hline Glacial & Permocarbonífero & $295 \mathrm{~m} . \mathrm{a}$. & Proterozoico \\
Glacial & Carbonífero inferior & $350 \mathrm{~m} . \mathrm{a}$. & \\
Glacial & Ordovícico & $440 \mathrm{~m} . \mathrm{a}$. & $700 \mathrm{~m} . \mathrm{a}$. \\
\hline Glacial & Precámbrico & $2,000 \mathrm{~m} . \mathrm{a}$. & \\
\hline Glacial & Primera glaciación & & \\
\hline
\end{tabular}

Figura 1. Glaciaciones e interglaciaciones sufridas por la Tierra desde el Proterozoico, es decir 2,000 millones de años.

Fuente: $<$ http://es.wikipedia.org/wiki/Edad_de_Hielo $>$.

Igualmente el aire aprisionado en los núcleos de hielo extraídos tanto en la Antártida como en Groenlandia han aportado grandes conocimientos sobre los climas del pasado en nuestro planeta. E. Brook, geólogo de la Universidad Estatal de Oregon, Estados Unidos, dice que los registros así obtenidos muestran los cambios climáticos que ha sufrido la Tierra en los últimos 650,000 años, algo que era impensable hace tan solo diez años. Estos estudios ahora permiten establecer los cambios, sus fluctuaciones y las fuerzas que lo han propiciado (Brook et al., 2011).

Por último señalemos que las costas y litorales actuales son el producto de la última variación eustática del planeta conocida como transgresión Flandense. Durante el periodo Holoceno desaparecieron primeramente el inlandsis fino escandinavo hacia el 8,000 B.P., luego el inlandsis Laurentino de los Grandes Lagos americanos hacia 7,000 B.P. y por último el importante inlandsis del norte de Siberia hacia 6,500 B.P. haciendo que el nivel marino subiera unos 130 metros (Delort et al., 2001). 


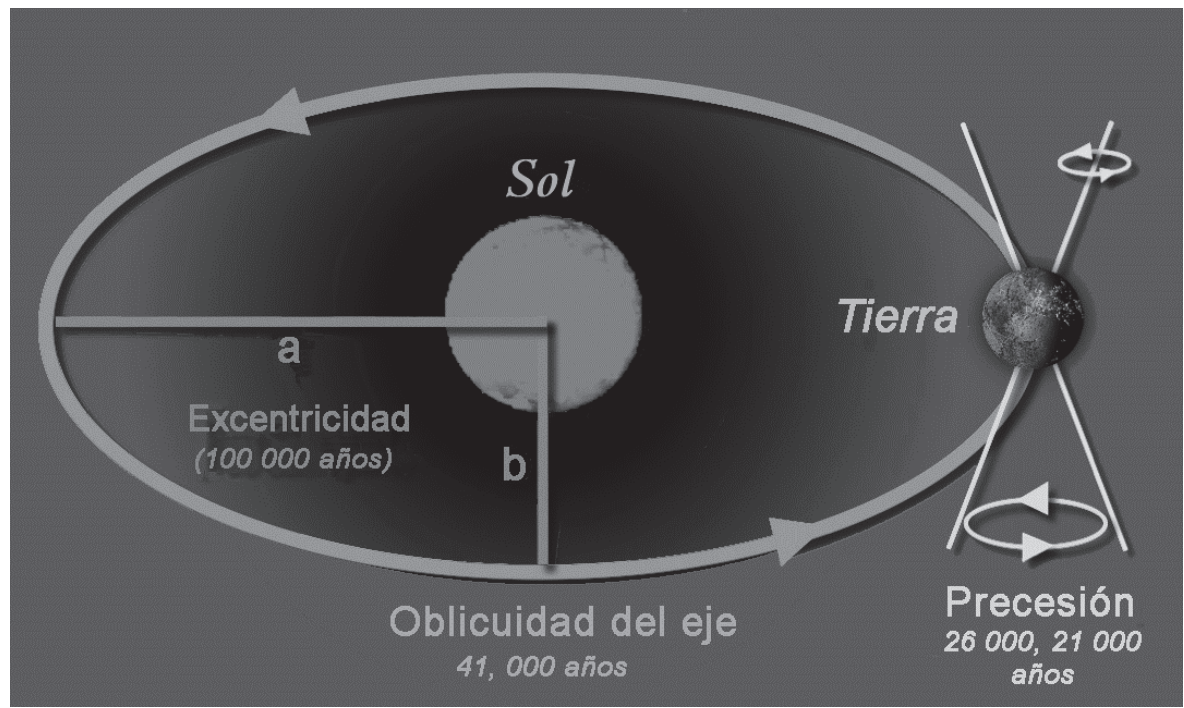

Figura 2. Esquema de las variaciones de la órbita terrestre según Milankovitch.

Fuente: Escuela de Geografía, Universidad de Costa Rica (UCR), 2013.

\section{Las glaciaciones en Costa Rica}

Los vestigios de glaciaciones en las altas cumbres de la cordillera de Talamanca ya no dejan la menor duda sobre la existencia de un casquete de hielo que se estacionó en la región de Chirripó (3,819 metros de altitud) y en el sector del cerro Fábrega (3,335 metros de altitud). Los circos glaciares, los valles en U, las morrenas y los tarns o lagos posglaciares son testigos mudos de este acontecimiento que lo hacen inegable. Al menos dos estacionamientos glaciares se han sucedido en Talamanca y correponden a las glaciaciones Riss y Wurm. A $10^{\circ}$ de latitud Norte ello se hace posible debido a la altitud que fue alcanzada por las altas cumbres de Talamanca gracias a la orogénesis, que levantó este sector de la placa tectónica del Caribe, por los empujes hacia el norte de la placa tectónica de Cocos que se subduce bajo la placa del Caribe (Bergoeing et al., 2012).

El valle de El General es una vasta depresión tectónica que se presenta como un sinclinal de orientación WNW-ESE. Algunos geólogos (Denyer et al., 2007) lo consideran como un monoclinal basculado. Ambos fenómenos están ligados al choque de las placas del Coco y del Caribe. La primera se subduce bajo la segunda, habiéndola levantando violentamente en los últimos tres millones de años, es decir desde fines del Terciario. Este fenómeno de colisión de placas, bastante reciente desde el punto de vista geológico, es capital para la comprensión del depósito a lo largo del Cuaternario de vastos conos de deyección a los pies de la vertiente SW de la cordillera de Talamanca. 

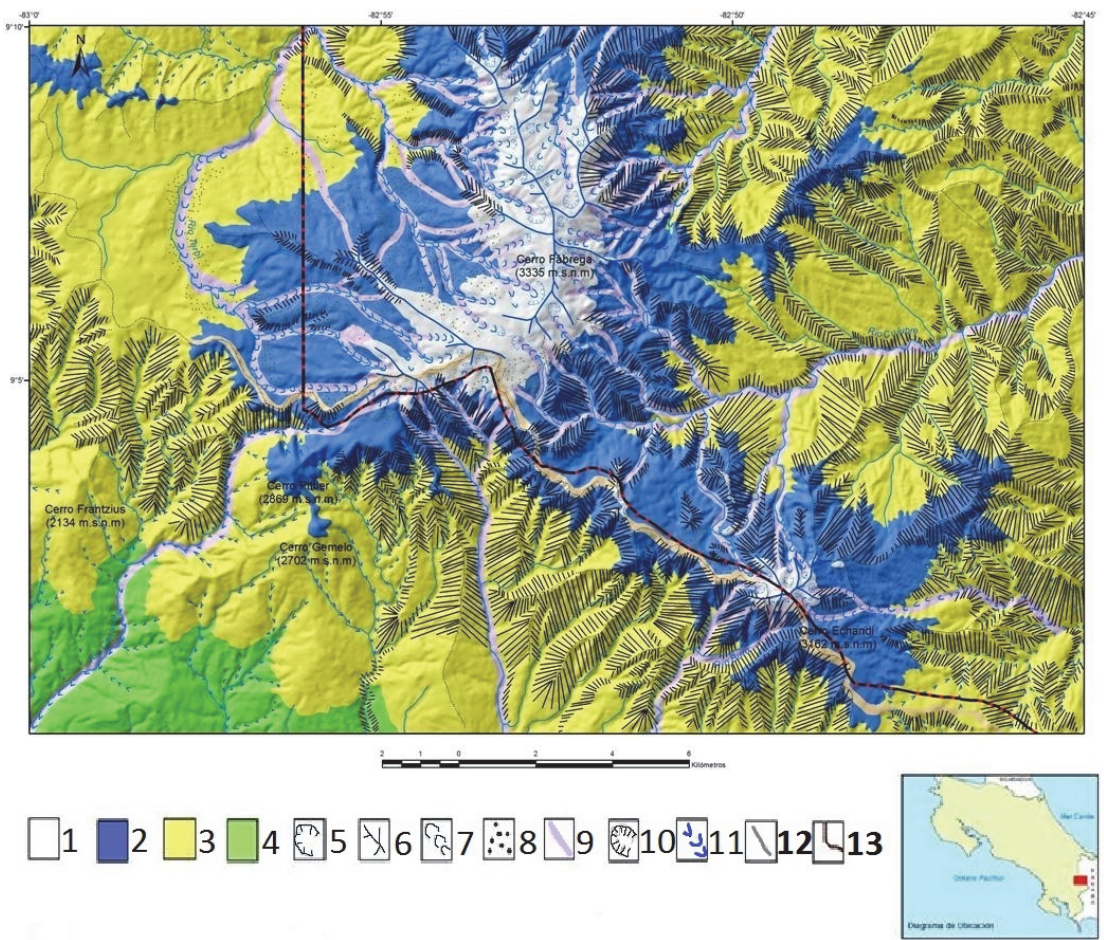

1.-Área Paleo.-glaciar Riss y Wurm. 2.- Área Paleo.-nivale Riss y Wurm. 3.- Área de paleopáramos. 4.- Área de paleo-sabanas de altitud. 5.- Pequeños circos glaciares. 6.- Divisorias glaciares con pequeños horns. 7.- Valles en U. 8.- Depósitos merrénicos. 9.- Recorrido de las lenguas glaciares con morrenas. 10.- Taludes de erosión. 11.- Valles en V. 12.- Líneas divisorias de aguas. 13.- Límite internacional Costa Rica-Panamá.

Figura 3. Máxima extensión de los glaciares en la cumbre del cerro Fábrega durante la glaciación Wurm (frontera Costa Rica-Panamá).

Fuente: Cartografía geomorfológica, J.P. Bergoeing, 2011.

Dos factores esenciales han dado origen y modelado los abanicos aluviales del sector: la orogénesis cuaternaria que se prosigue muy activamente de nuestros días alcanzado la altitud máxima de 3,820 metros en el Chirripó y al menos las dos últimas glaciaciones; Riss $-200,000$ años a $-120,000$ años y Wurm $-90,000$ a $-12,000$ años, que permitieron durante esos largos lapsos de tiempo la acumulación y formación de un casquete importante de hielo en altas cumbres. Los periodos interglaciares RissWurm -120,000 años a -90,000 años y el actual poswurmiense desde hace 12,000 años son periodos relativamente cortos, pero durante el cual el deshielo es súbito por el cambio climático y recalentamiento de las altas cumbres. Tal deshielo brutal es responsable de los conos de deyección modernos a los pies de la cordillera de Talamanca. 


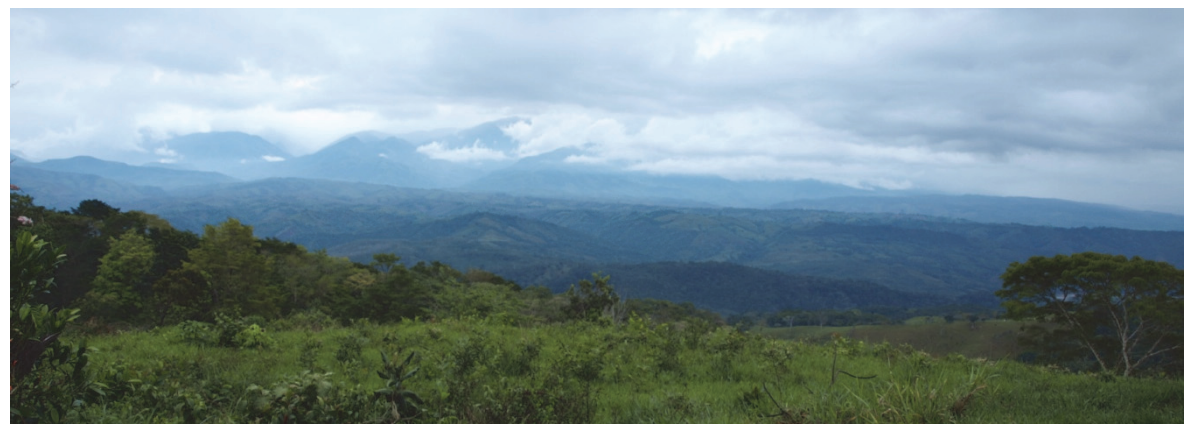

Figura 4. Perfil general de los conos de deyección que bajan de Talamanca constituyendo espesores considerables, producto de las masas deslizadas por el deshielo cordillerano de las dos últimas glaciaciones y periodos interglaciares (fotografía: J.P. Bergoeing).

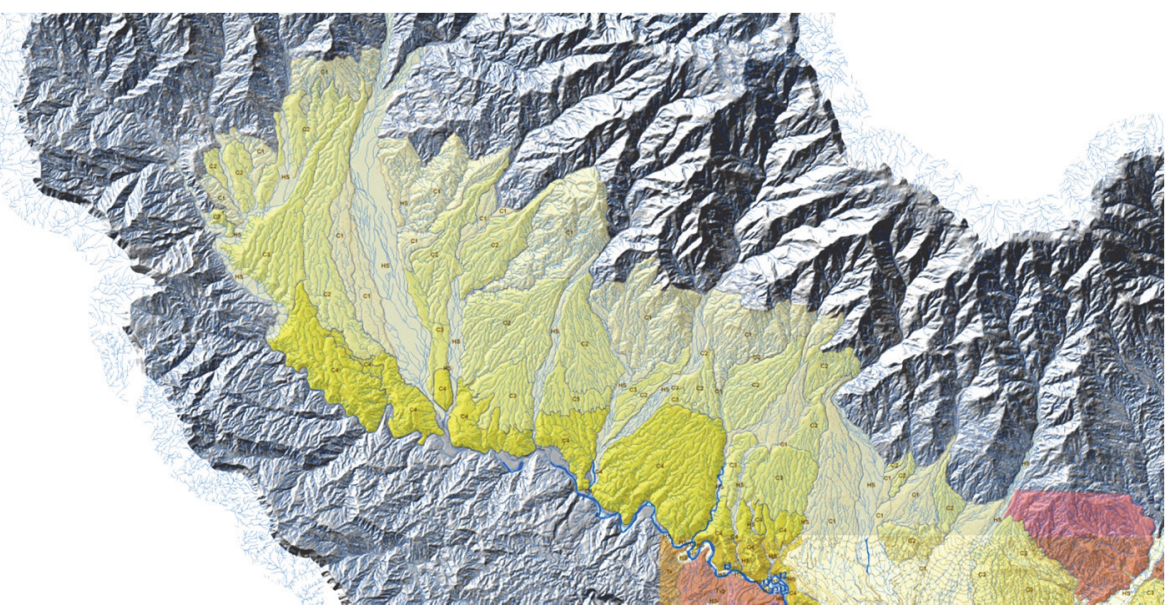

Figura 5. Conos de deyección del valle de El General donde se reconocen cinco procesos de colmatación que van desde el Pleistoceno inferior (C4) pasando por el Pleistoceno medio (C3), Pleistoceno superior (C2 y C1) y Holoceno (HS) (mapa: J.P. Bergoeing).

\section{Los conos de deyección del Pleistoceno inferior a medio, C4 y C3}

Son el resultado de depósitos de vertientes, por efectos de la erosión producida por intensas lluvias tropicales, en el incipiente relieve volcánico-sedimentario de la cordillera de Talamanca, en pleno levantamiento orogénico y por ello son los más antiguos del sector ya que van del Pleistoceno inferior al Pleistoceno medio. Se presentan hoy como depósitos de arcillas rojas (ilíticas a montmorilloníticas) que forman una 
matriz que encierra cantos rodados de gran calibre (de 20 a $40 \mathrm{~cm}$ de diámetro), que se encuentran totalmente alterados (fantasmas) y que al golpe de piqueta se funden con la matriz que los rodea. Sin embargo los depósitos se encuentran basculados en sentido opuesto a la corriente de lodo que los depositó (Battistini y Bergoeing 1983) lo cual demuestra el buzamiento actual que afecta a este nivel antiguo. Los conos C4 al momento de crearse el depósito chocaron con un pequeño relieve volcánico que emergía del Océano Pacífico cuyo litoral se encontraba en las cercanías de lo que hoy es el río General. Estas formaciones volcánicas cuyos exponentes son el volcán Mano de Tigre (Bergoeing et al., 1978) o el China Kichá (Bergoeing et al., 2010) son el producto de ascensión magmática fisural gabroica-basáltica del fines del Plioceno, comienzos del Pleistoceno producida por el empuje y colisión de la placa del Coco con la del Caribe en este sector. En las estribaciones del Pacífico de Talamanca

las rocas volcánicas del Plioceno pleistoceno corresponden a rocas y edificios volcánicos que se sitúan desde el cerro Kai hasta el sector entre fila Cabagra y el poblado de Puente, lo mismo que en una franja desde la ladera sur de fila Chimbeta hasta el área al este de fila Colorado próximo al límite con el cantón de Coto Brus, así como el sector aledaño al poblado de Volcancito (Subredes, UNA, 2006).

En el Pleistoceno medio, siempre gracias a los empujes verticales de la orogénesis el cono C4, se vio recubierto por un nuevo depósito aluvial (C3) igualmente de gran espesor y de características similares al anterior. En el sector de la ciudad de Pérez Zeledón los conos se depositaron lateralmente por efectos de un basculamiento tectónico NW-SE que coloca los depósitos del más antiguo al más reciente de manera paralela al río Chirripó del Pacífico.

El cono T3, que cronológicamente se superpone al cono T4, es lógicamente más reciente y tentativamente puede ser clasificado como del Pleistoceno medio. Los cantos rodados que lo componen y permiten identificarlo, aunque muy alterados, son reconocibles y mantienen una cierta cohesión. Igualmente están insertos en una matriz arcillosa rojo-parda pero no tan intensa como la de T4. Es un cono más difícil de reconocer en el campo por estar recubierto en partes por los conos más modernos T2 y T1, estos últimos que situamos en el Pleistoceno superior. De ellos uno de los más interesante es el abanico aluvial T1 del sector aledaño al contacto cordillerano del río Unión, por cuanto está recubierto por enormes bloques granodioríticos, (del tamaño de una casa) sumamente erosionados formando pseudo-lapiaces por efectos de la erosión pluvial. Estos megabloques de unos 10 x 30m y $3 \mathrm{~m}$ de alto son la consecuencia del deshielo poswurmiense de Talamanca y marcan deslizamientos brutales y súbitos del material arrancado a las cumbres del Chirripó por efecto de las lluvias diluviales acaecidas con el cambio climático de ese periodo. Actualmente el modelado geomor- 
fológico de la superficie superior de los conos se presenta como un modelado multiconvexo, mientras que el sector que domina la vertiente NW del río General forma escarpes de erosión alternados por los niveles de las terrazas fluviales donde distinguimos tres niveles. Dichos niveles son probablemente climáticos pero asociados con la fuerte tectónica de alzamiento por cuanto una cronología absoluta sería difícil de aplicar al conjunto de los niveles fluviales y más bien se debería proceder a un trabajo local de caso por caso (véase Figura 6).

\section{Los conos del Pleistoceno superior T2 y T1}

Son la consecuencia de la orogénesis de Talamanca, que durante el Pleistoceno superior alcanza altitudes importantes, superiores a los 3,000 metros y en donde al menos dos estacionamientos glaciares acumularon masas de hielo importantes y de espesores considerables. Por la latitud de Costa Rica, los periodos interglaciares RissWurm o Sangamoniano para América del Norte (-130,000 a -110,000 años) y poswurmiense (-12,000 años en adelante) o postwisconsiniano, provocaron el derretimiento acelerado de la masa glaciar creando las condiciones de deslizamientos en masa de grandes bloques graniodioríticos y del material mueble que se encontraba a menor altitud. Todo este material se acumuló en los piedemontes de Talamanca, preferentemente en el sector SW (vertiente del Pacífico) donde la acumulación alcanzó espesores considerables de material caótico, llegando en algunos sectores a medir de 200 a 500 metros de espesor.

\section{Los conos actuales ( HS)}

Se trata de conos en formación donde discurren los principales afluentes del río El General. Se caracterizan por superponerse sobre los más antiguos siguiendo una dirección NNE-SSW a excepción del río Chirripó, orientado por un basculamiento tectónico y por disponerse en forma alargada. El sistema de conos de deyección se prosigue más al SW de Paso Real donde los afluentes del río Coto Brus y Cotón han erosionado profundamente el material caótico de los abanicos y en donde sobresalen algunas estructuras volcánicas probablemente del Plioceno. La ciudad de San Isidro de El General, rebautizada como Pérez Zeledón, está construida sobre un gran abanico aluvial construido por el río Chirripó del Pacífico que confluye con el río El General. La observación de imágenes satelitales han permitido identificar una serie de cuatro niveles de abanicos que se disponen en forma paralela. La serie está basculada por efectos de la Neotectónica elevándose hacia el NW. Poseen una matriz fina arcillosa roja, con algunos elementos gruesos rodados para los más antiguos mientras que los niveles más jóvenes se caracterizan por un abundante material rodado fluvial, de litología diversa que descansan aflorantes o sobre una matriz pardo oscura. 
Los ríos afluentes de El General al llegar a la zona de confluencia, se encajonan profundamente en los conos antiguos, particularmente el nivel $\mathrm{C} 4$, en donde constituyen cañones fluviales. Desde el río Unión, pasando por los ríos Volcán y Ceibo y continuando hacia el SW, los ríos se encañonan durante varios kilómetros hasta alcanzar la confluencia con el río El General. En algunos casos en las zonas de confluencia constituyen abanicos coluviales como es el caso para el río Volcán. Ello se debe al basculamiento general que ha sufrido el sector por efectos del avance de la placa del Coco que se subduce bajo la del Caribe. En general el material depositado es de tipo fluvial y torrencial, en algunos sectores la roca madre aflora en los talwegs dejando en evidencia la profunda erosión fluvial asociada con una tectónica positiva muy activa.

El piedemonte Pacífico del valle de El General es un sector privilegiado en Costa Rica por la presencia de los conos de deyección o abanicos aluviales que lo conforman. Ellos son el testigo mudo de los depósitos que se han formado de modo correlativo a lo largo del Cuaternario, cosa muy difícil de encontrar en otras partes del país. El sector amerita un estudio sedimentológico detallado de los diferentes depósitos, lo que permitiría establecer una cronología precisa de cada evento, estudiando y clasificando por ejemplo pólenes, o buscar mediante sondajes la presencia del isótopo ${ }^{18} \mathrm{O}$, (el isótopo ${ }^{18} \mathrm{O}$ es un indicador paleoclimático utilizado para conocer la temperatura de una región en una época dada, más elevada es la relación isotópica ${ }^{16} \mathrm{O} /{ }^{18} \mathrm{O}$ y más baja es la temperatura correspondiente. Esta relación puede ser determinada mediante muestras de aragonita y de calcita contenida en algunos fósiles. $\mathrm{Y}$ por dataciones radiométricas de 14C (el Carbono-14, derivado de la relación $12 \mathrm{C} / 14 \mathrm{C}$ ) y por el método $\mathrm{K} / \mathrm{Ar}$ de algunas muestras asociadas.

\section{Relatos míticos de antiguas civilizaciones}

El relato mítico más antiguo data del siglo $\mathrm{V}$ a.C. y es sin lugar a dudas el del fílósofo griego Platón, el cual nos relata en sus obras Critias y Timeo la historia de la Atlántida, antigua civilización que fue engullida en el mar. Según Platón el relato le fue comunicado por Solón de Atenas, el cual obtuvo la información de los sacerdotes del templo de Sais en Egipto. La Atlántida poderosa ciudad que se situaba más allá de las columnas de Hércules (hoy Gibraltar), es decir en alguna parte del Atlántico Norte desapareció bajo el mar. Una explicación moderna de ese fenómeno nos lo da la geomorfología. En efecto, sabemos que durante las glaciaciones el nivel marino se encontraba entre 120 a 140 metros por debajo del nivel marino actual, ello porque las masas de hielo de los casquetes polares e inlandsis continentales absorbieron parte de la masa líquida existente. Por ello indudablemente Atlantis debió existir al menos durante el periodo glaciar Wurm es decir entre 90,000 a 12,000 años. Digo debió existir, así como hoy tenemos el conocimiento de Troya descubierta por el arqueólogo aficionado alemán Heinrich Schliemann (1822-1890) quién buscó la ciudad 
mítica de Homero relatada en la Iliada y por ello fue burla de los arqueólogos de la época. Descubrió en 1873 el Tesoro de Priamo en Hisarlik, Turquía a orillas del estrecho de los Dardanelos. Posteriormente descubrió la otra mítica ciudad de Micenas.

Otro personaje del siglo XIX fue la controversial rusa Helena Blavatsky (18311891), fundadora de la Sociedad Teosófica. Su libro más famoso La doctrina secreta, describe la evolución humana (antropogénesis) y da a conocer las civilizaciones Lemúrida y Atlante.

Un tercer personaje interesante en citar es sin lugar a dudas el norteamericano Edgar Cayce (1877-1945), nacido en Kentuky, fotógrafo de profesión pero que se hizo famoso como vidente y psíquico. El "profeta dormido" entre muchas de sus declaraciones en estado dormido hace descripciones de la Atlántida y profetiza que a partir de 1998 la Tierra conocerá grandes cambios continentales (Kirkpatrick, Sidney D., 2000).

Desde entonces han surgido nuevos descubrimientos arqueológicos que replantean la historia de la humanidad. En 2008 la investigadora física, doctora Anna Pazdur, de la Universidad de Silesia en Polonia, revela al mundo la pseudo existencia de las "pirámides" de Bosnia cuyas dataciones al 14C remontarían esta civilización a 29,000 años, es decir, en plena era glaciar wurmiense! Así en Bosnia el antropólogo, doctor Semir Osmanagich, afirma que nuestra historia oficial es falsa, "la evidencia encontrada a través del mundo de una especie humana altamente evolucionada desde antes de la edad de hielo, demanda un reconocimiento científico de nuestro pasado, que representa a sociedades de una avanzada cultura y tecnología”. El valle de las pseudo pirámides de Bosnia se extiende por $6 \mathrm{~km}^{2}$ en la cuenca del rio Visoko a $40 \mathrm{~km}$ al norte de Sarajevo la capital, y ya suscita una agria polémica en el mundo intelectual.

Otro de los descubrimientos más desconcertantes fue el de las piedras de Ica en Perú, donde el doctor Cabrera reunió más de 15,000 objetos. Se trata de basaltos grabados con diferentes personajes y animales prehistóricos. La comunidad científica tras estudiarlos detenidamente los consideró un fraude por su elaboración reciente encontrándose trazas de lijado y pintura además no se conoce el lugar donde fueron encontradas (véase Figura 7).

Cabe citar los últimos descubrimientos arqueológicos de una nueva civilización en Carahunge, Armenia que se remontaría a 5,000 años. El lugar se sitúa próximo a Sisian a $200 \mathrm{~km}$ de Erevan, capital de Armenia y fue estudiado en 2,000 por un equipo de arqueólogos del Institut für Vorderasiatische Archäologie de la Universidad de Munich, Alemania. Se le considera el Stonehenge de Armenia por ser una necrópolis de la Edad del Bronce medio a la Edad del Hierro. El gran círculo de piedras ha sido datado de 5,500 a.C. y sería un vasto observatorio astronómico donde estarían consignados los movimientos del Sol, la Luna y las estrellas. 


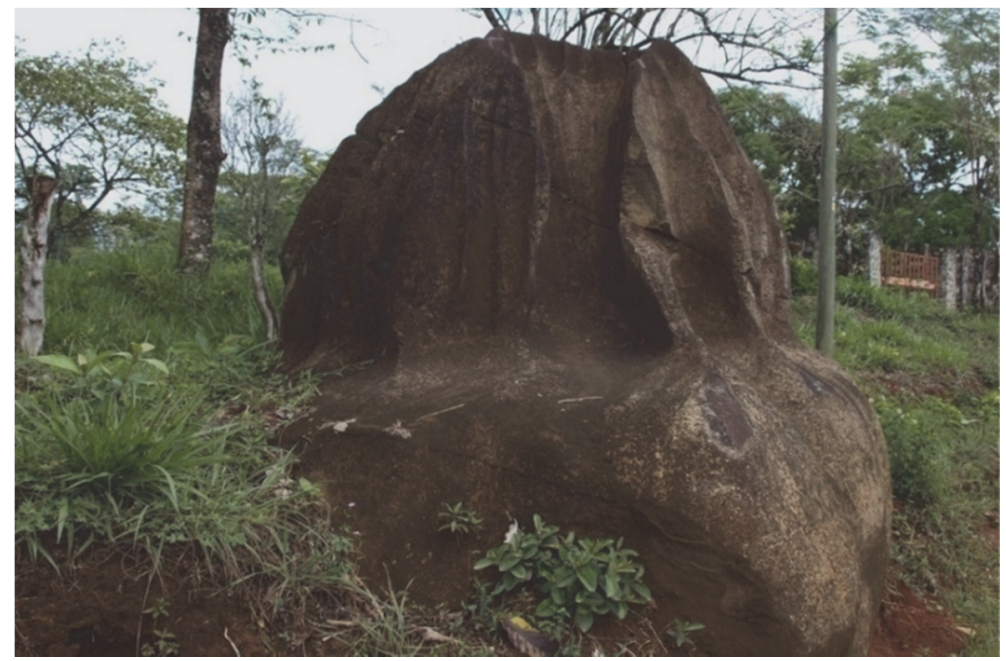

Figura 6. Bloque errático granodiorítico del sector río Volcán cuyas facetas están erosionadas por la acción pluvial del deshielo poswurmiense formando pseudolapiaces (fotografía: J.P. Bergoeing).

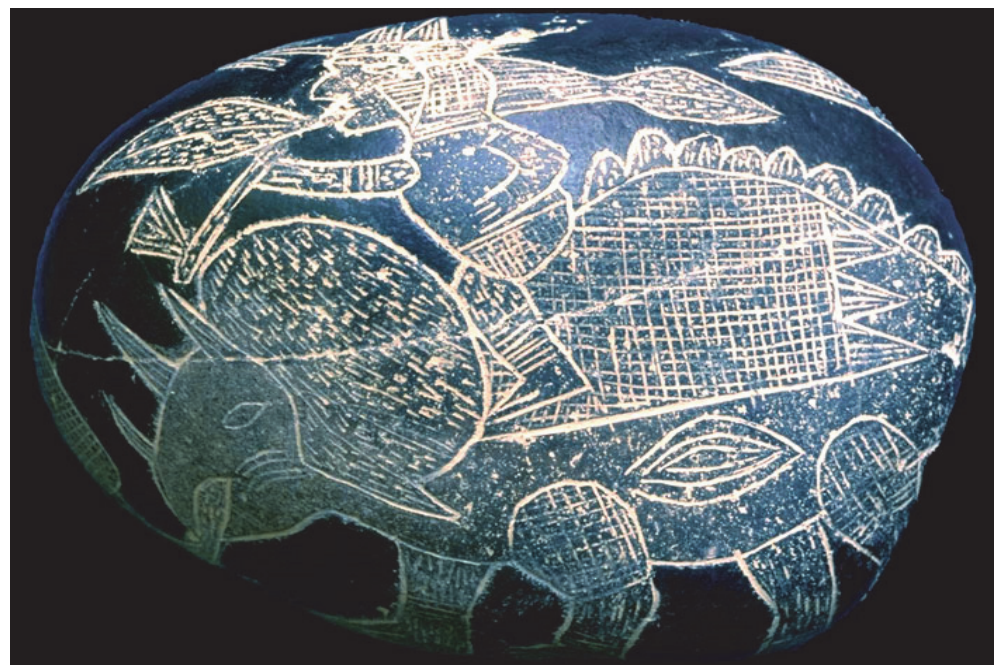

Figura 7. Piedra de Ica. Falsificación que representa a un triceratops cabalgado por un hombre. Este animal prehistórico despareció hace más de 65 millones de años, durante el Cretácico.

Fuente: <http://calendariomayaplus.blogspot.com/2011/06/las-piedras-de-icauna biblioteca.html>. 


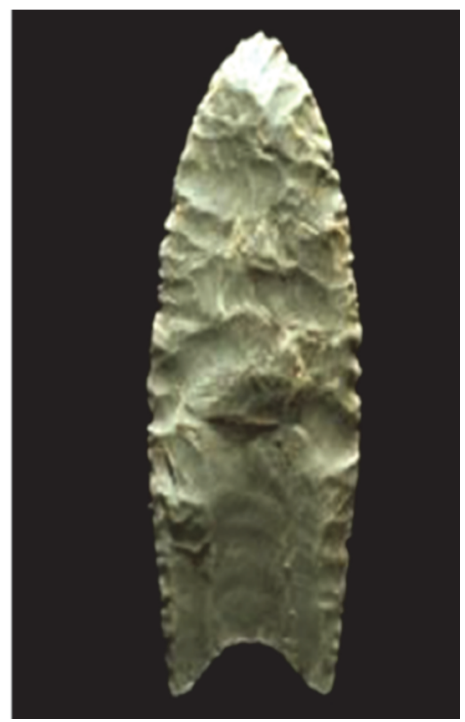

Figura 8. Punta de flecha de la cultura clovis de América del Norte.

Fuente: $<$ http://www.doslourdes.net/monogr\%C3\%A1 ficos-primeras-culturasdel-mundo-am $\%$ C3\%A9rica..pdf $>$.

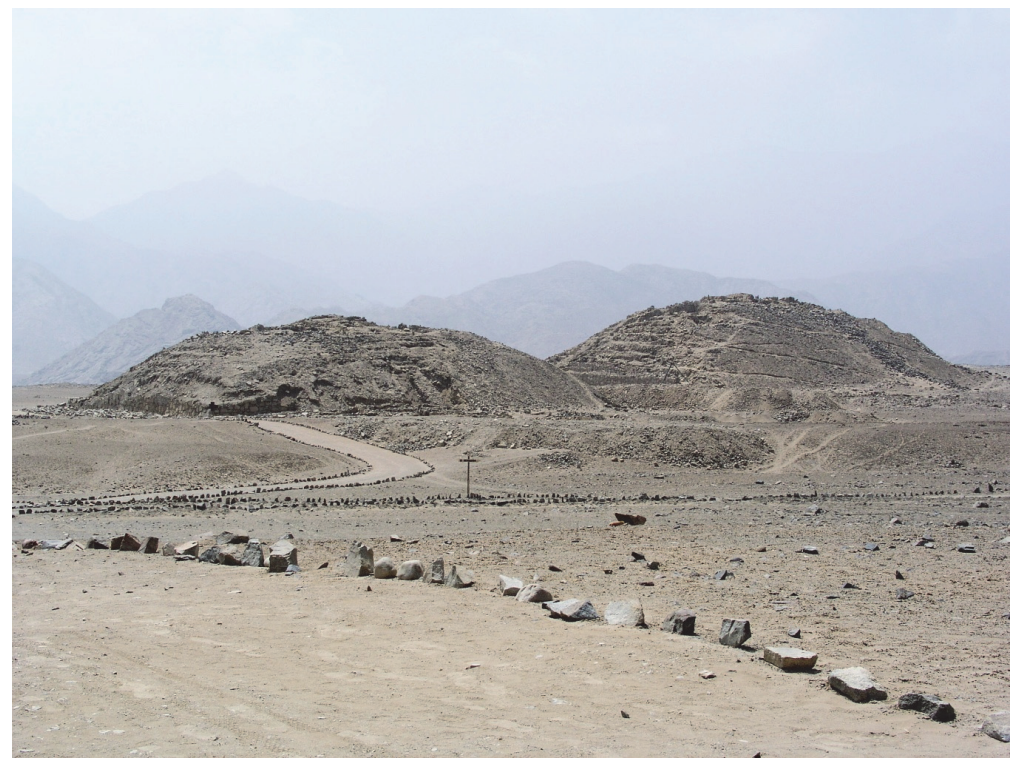

Figura 9. Pirámides de la cultura caral, Perú.

Fuente: $\quad<$ http://upload.wikimedia.org/wikipedia/commons/3/30/PeruCaral01. jpg>. 


\section{Las migraciones intercontinentales}

El antropólogo italiano Yuri Leveratto (Barcelli, 2009), radicado en Colombia, ha realizado estudios en América Latina, que han aportado una nueva visión al poblamiento continental y deduce que el hombre americano es el resultado de múltiples orígenes poniendo fin al único poblamiento de origen asiático a través de las praderas de la Beringia, hoy estrecho de Bering, hace unos 12,000 años es decir al final de la última glaciación.

Así los últimos descubrimientos en Pedra Furada, Brasil, testimonian de un aporte africano al poblamiento de América del Sur, estudiado por el equipo franco-brasileño de arqueólogos dirigido por Niede Guidon quien en 1973 encontró restos humanos pertenecientes a Homo Sapiens arcaicos de África: las dataciones de Niede Guidon en 1986 (Guidon y Delibras, 1986) llevan las dataciones de 48,000 a 32,000 B.P., y podrían extenderse hasta 60,000 años!

Una tercera teoría complementaria indica que el hombre americano habría llegado navegando a través del Pacífico (Melanesia y Polinesia) y ello está soportado por pruebas antropológicas, etnográficas y lingüísticas. El etnólogo y lingüista francés Paul Rivet (1876-1958) ha comprobado a través de sus estudios las analogías lingüísticas con indonesios, melanesios y polinesios. Estudiando al grupo lingüísticos Hoka que va de Oregon a Centroamérica descubrió más de 280 semejanzas en vocablos y formas gramaticales.

Una explicación de estos viajes transpacíficos los da la geomorfología puesto que durante la glaciación Wurm (90,000 a 12,000 B.P.) el nivel del mar se encontraba 130 metros por debajo del nivel actual y con ello un sinnúmero de islas existían hoy desaparecidas bajo las aguas oceánicas.

Una prueba del poblamiento muy antiguo de América nos lo da la cultura Monte Verde en Chile. En efecto Monte Verde es un yacimiento arqueológico a $30 \mathrm{~km}$ de Puerto Montt en el sur de Chile, descubierto en 1975 y estudiado por Félix Werner y Carlos Jünger cuyas dataciones 14C más antiguas se remontan a 33,000 B.P. (Dillehay et al., 2008).

En Estados Unidos, el descubrimiento de coprolitos humanos en una cueva de Oregon fechados a través del método 14C y fragmentos de ADN mitocondrial humano recuperado de las heces vinculan las muestras a dos subgrupos genéticos surgidos entre 14,000 a 18,000 años B.P. (Gilbert et al., 2008) y que son anteriores a la cultura clovis. Las cavernas de Meadocroft en Pensilvania, Estados Unidos, excavadas de 1973 a 1978 por James M. Adovasio indicaron una ocupación humana que según 14C se situaría entre $-19,000$ a $-16,000$ años y en donde se han encontrado restos de herramientas, animales y plantas. Finalmente en 2004, Albert Goodyear de la Universidad de Carolina del Sur, que trabaja desde 1980 en Topper, Carolina del Sur en utensilios primitivos de piedra haciendo retroceder la presencia humana con 14C a 50,000 B.P. y 37,000 B.P., sin embargo otros arqueólogos cuestionan sus des- 
cubrimientos. Igualmente restos humanos encontrados en Old Crow al norte de Yukón en Canadá, dan una antigüedad de 26,000 años.

De todas formas estos descubrimiento recientes abren la puerta a otros que no dudo serán la confirmación de una presencia humana más antigua en América, durante el último periodo glaciar y probablemente anterior es decir durante el interglaciar Riss-Wurm.

\section{La civilización actual desde el deshielo wurmiense hace 12,000 años}

Es indiscutible que desde hace 12,000 años cuando entramos definitivamente el último periodo interglaciar, conocido como Holoceno, nuestra civilización actual se ha ido desarrollando, con características climáticas parecidas a las de nuestros días, pero con periodos más cálidos y más fríos que se han intercalado. Los descubrimientos más recientes han puesto en tela de juicio la historia clásica que se nos ha enseñado.

Así en América hemos descubierto viejas civilizaciones que hacen la transición entre el periodo glaciar wurmiense y el Holoceno. Hipótesis como la llegada de los fenicios, chinos y japoneses, gracias a sus habilidades marítimas, siguen siendo de difícil demostración.

Estados Unidos: la cultura clovis descubierta en 1929 por Ridgely Whiteman en Nuevo México, fue reconocida en 1932 como una cultura del Pleistoceno en América del Norte con una antigüedad superior a los 13,500 años (véase Figura 8).

Mexico: en los hallazgos humanos más antiguos se encontrarían en la región de El Cedral, San Luis Potosí y tendrían según datación 14C una edad de 33,000 años. En efecto las excavaciones llevadas a cabo por la arqueóloga Lorena Mirambel en 1978 en el lugar ya citado revelaron restos de animales y herramientas hechas por el hombre que revelan la actividad humana más antigua de México (Pérez Crespo et al., 2009).

Costa Rica: la presencia humana en Costa Rica sería anterior a 12,000 años según análisis de datación de $14 \mathrm{C}$ realizada en 14 piezas de carbón y pedazos de madera, junto a vestigios de herramientas y armas talladas, en Siquirres en el sitio La Isla por el equipo de arqueólogos del Instituto Costarricense de Electricidad que trabajan en el proyecto hidroeléctrico reventazón dirigido por Marta Lucía Chaves Montoya. Las muestras fueron analizadas en el laboratorio Beta Analytic, de Miami (Florida, Estados Unidos).

Esto viene a confirmar que desplazamientos tempranos humanos se realizaron entre América del Norte y América del Sur, bordeando las costas que eran lugares acogedores y mucho más extensos, hasta el deshielo wurmiense donde el nivel del mar subió de 130 metros. Posteriormente, podemos citar la cultura del diquís famosa por sus esferas gigantes de piedra granodioríticas, que se instaló hace unos 6,000 años en la desembocadura del río Grande de Térraba. 
Perú: la cultura de caral que se desarrolló entre 3,000 a 1,800 a.C. es el surgimiento de la sociedad estructurada, más antigua de América, es un área de asentamiento urbano que abarca una extensión de $400 \mathrm{~km}$ en una serie de valles cuyos ríos desembocan en el Océano Pacífico. Destaca principalmente el valle de Supe ubicado en Barranca, Lima donde se identificaron 21 asentamientos. Esta civilización es contemporánea con la de Mesopotamia y Egipto, y antecede en 1,200 años a la cultura olmeca (véase Figura 9).

Hace 2,500 años el cambio climático afectó al mundo entero produciendo una acentuación de la sequía en las regiones intertropicales que pudimos comprobar gracias a dataciones 14C estudiando la geomorfología del sitio Hapex Sahel, Niger en 1993 a solicitud del Instituto de Investigación para el Desarrollo (IRD) de Francia. Ese periodo más seco se hizo presente igualmente en Perú.

Nazca: a 450km al sur de Lima, entre Palpa y Nazca, en la pampa de Socos, se desarrolló entre el siglo I y VI de nuestra era (según dataciones 14C) una antigua cultura conocida como "cultura de nazca". Esta cultura dejó trazados gigantescos sobre $520 \mathrm{~km}^{2}$. Se trata de dibujos de unos $20 \mathrm{~cm}$ de espesor sobre el suelo árido de la pampa peruana donde están representadas más de 800 figuras de animales. Descubiertos en 1927, por el arqueólogo peruano Toribio Mejia Xesspe, que las divisó de las colinas circundantes. Datarían de 200 a.C. María Reiche (1903-1998) antropóloga alemana, dedicó toda su vida al estudio de las líneas de Nazca (véase Figura 10).

Mucho más al sur, en la región de Tarapacá, Chile, existen muchos otros geoglifos y entre ellos destaca el "Gigante de Atacama" de 84 metros de largo trazado en la ladera noreste del cerro Unita a $15 \mathrm{~km}$ del pueblo de Huara. Sería la representación de Tonapa o Tarapacá un predicador preincaico.

Finalmente, al noreste de China en Horquín se han puesto al descubierto en 2010 casas y tumbas prehistóricas de la cultura hognsan y que se remontan a 5,000 años. Con ello vemos que el urbanismo es algo inherente a la cultura humana y que se remonta a miles de años, siendo el plan damero el primero utilizado por el ser humano como lo podemos observar en las urbes de Mesopotamia y en Mohenjo Daro, India.

\section{Migraciones anteriores a Cristobal Colón}

\section{Fenicios en Brasil}

Sin embargo en Brasil hay evidencias arqueológicas de la presencia de fenicios, grabadas Alto en la Piedra de Paraiba en Pouso descubierta en 1872. La Piedra habiéndose destruido pero su transcripción salvada era considerada falsa. En 1960, el epigrafista estadounidense Cyrus Gordon demostró que la transcripción era auténtica porque transmitía conceptos gramaticales de la lengua fenicia totalmente desconocidos en 1872 fecha del descubrimiento de la piedra He aquí una traducción: 
Somos Cananeos de Sidón de la ciudad del rey mercante. Llegamos a esta isla lejana, una tierra montañosa. Sacrificamos un joven a los dioses y diosas celestes, en el decimonoveno año de nuestro rey Hiram y nos embarcamos en Ezión-Geber en el Mar Rojo. Viajamos con diez naves por dos años alrededor de África, luego fuimos separados por la mano de Baal y ya no estamos con nuestros compañeros. Así llegamos aquí, doce hombres y tres mujeres, a la isla del hierro, en una nueva playa que yo, el almirante, gobierno. Pero seguramente los dioses y diosas nos favorecerán.

Según Cyrus Gordon el rey citado sería Hiram III ( 531 a.C.), (Gordon 1971).

Otra inscripción fenicia de Brasil es la Piedra de Gavea en Barra de Tijuca en Rio de Janeiro. Los petroglifos fueron parcialmente descifrados por Bernardo de Azevedo da Silva Ramos en 1932 (Silva Ramos 1932) donde dice: “Aquí Badezir, rey de Tiro, el hijo más viejo de Jetbaal” (Jetbaal reinó hasta el 847 a.C).

Sabemos por los papiros egipcios que el Faraón Necao II (610-595 a.C) encomendó a los fenicios la exploración de la costa africana y que al menos dos periplos alrededor de ese continente se completaron saliendo del mar Rojo y retornando a Egipto por Gibraltar. Es posible que la ruta inversa fuera ya conocida por los fenicios y haber sido emprendida pero algunos barcos desviados por los Alisios hacia el Oeste, es decir Brasil, como le sucedió a la expedición de Pedro Alvarez Cabral que “descubrió” el Brasil en el año 1,500.

\section{Civilización amazónica}

En la frontera entre Brasil y Bolivia se han encontrado trazas arqueológicas de una antigua civilización amazónica que se remontaría a 200 a.C. y se habrían prolongado hasta fines del siglo XIII. Se trata de un conjunto urbano de 260 avenidas, lagos y canales de riego. Cubre $240 \mathrm{~km}^{2}$ y habría albergado unas 60,000 personas. El conjunto es estudiado por Denise Schaan de la Universidad Federal de Pará, Belem, Brasil.

Entre los años 950 y 1,250 d.C. la Tierra experimentó un alza de temperaturas de $1.5^{\circ} \mathrm{C}$ conocido como "periodo cálido medieval", es durante este tiempo que las expediciones vikingas exploraron el Atlántico norte, llegando hasta Canadá, que bautizaron como Vinland o tierra de los viñedos. En 1960 en la "Anse aux Meadows", en Terranova, Canadá fue descubierto un asentamiento vikingo testimonio de la presencia nórdica temprana, en esta parte de América, el sitio fue declarado patrimonio de la humanidad por la Organización de las Naciones Unidas para la Educación, la Ciencia y la Cultura (UNESCO) (véase Figura 13).

A partir del 1250 y hasta 1850 el planeta sufrirá lo que se conoció como la pequeña Edad del Hielo y que afectará a Europa especialmente en el siglo XVI y XVII provocando grandes hambrunas. Se caracterizó por tres recurrencias frías; 1645 1715,1770 y 1850 . Ello debido a un aumento de la actividad volcánica mundial y disminución de la actividad solar. 


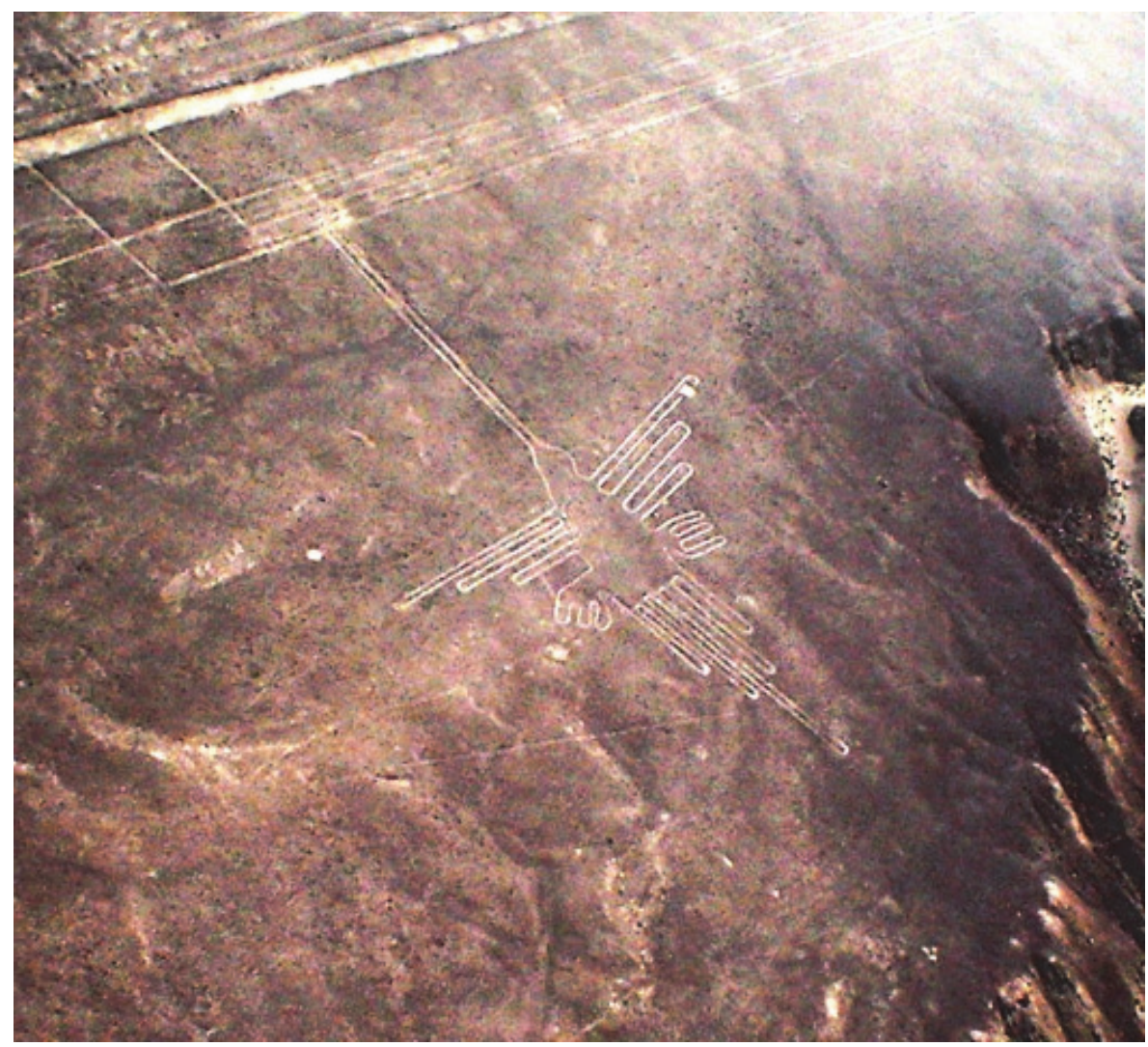

Figura 10. El Colibrí trazado y excavado sobre el suelo árido de la pampa de Nazca, probablemente con cuerdas. Algunas líneas pueden medir hasta 275 metros de largo.

Fuente: $\quad<$ http://es.wikipedia.org/wiki/Archivo:Lignes_de_Nazca_Décembre_ 2006_-_Colibri_1c.jpg>.

Por último citemos al almirante chino Zheng He (1371-1433) el cual realizó siete expediciones navales a partir de Nankin entre 1405 y 1433 y con una cantidad impresionante de navíos entre 50 y 300 que llevaban unos 30,000 tripulantes y recorrió las costa del África y el Océano Índico hasta las de América en el Pacífico. Los chinos no crearon colonias por no tener interés en expandirse fuera de su territorio influenciado por el aislacionismo de la sociedad confucionista y las constantes amenazas en sus fronteras. El viaje a América de 1421 es una hipótesis de Gavin Menzies meramente especulativa que no ha sido probada hasta hoy. 

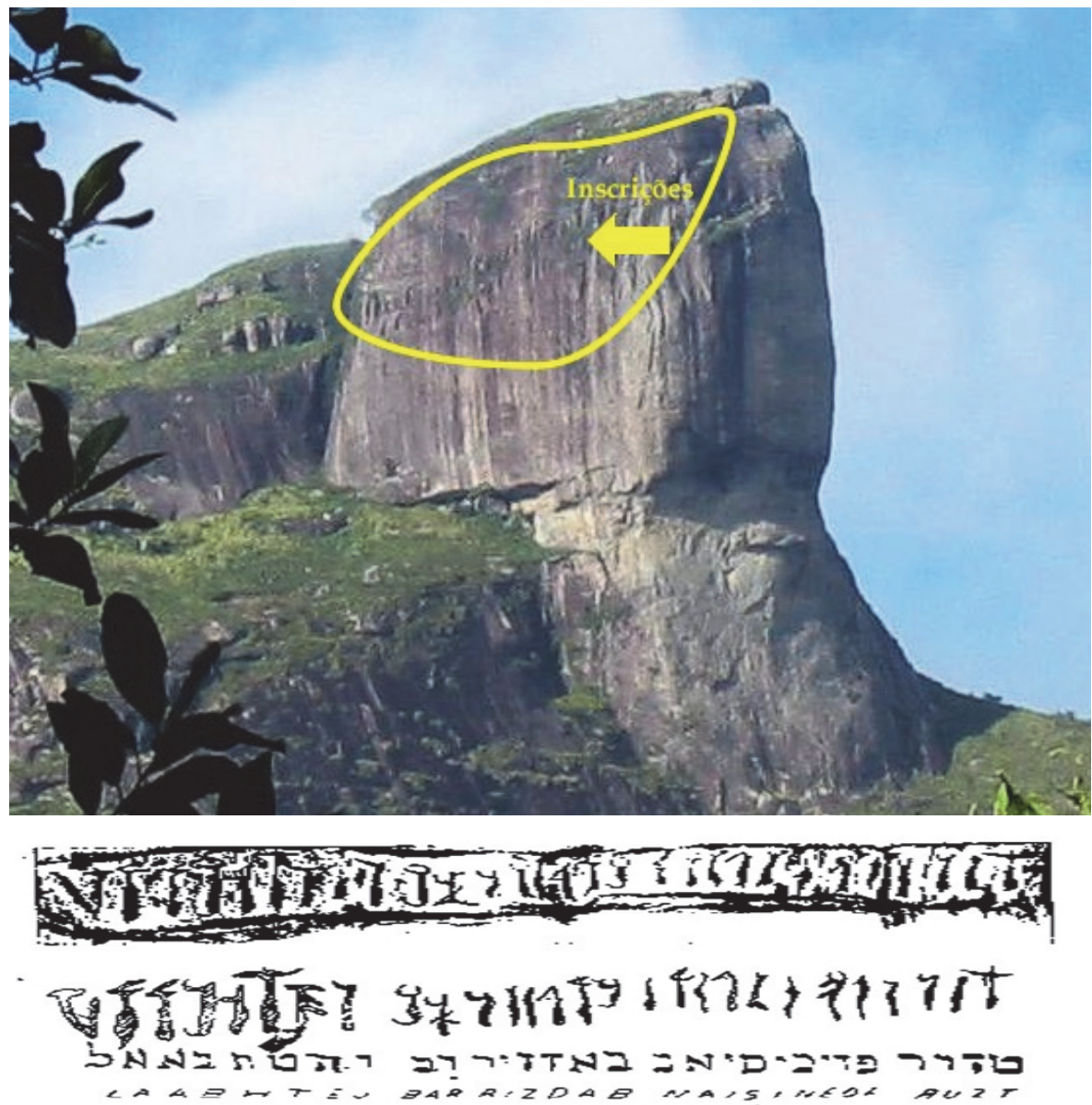

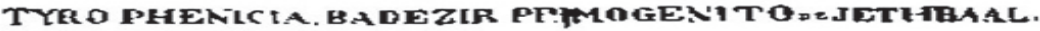

Figura 11. Petroglifo de la Piedra de Gavea en Barra de Tijuca, Río de Janeiro, Brasil descubierto en 1932, reproducción y traducción de las inscripciones en escritura fenicia por Berbardo de Azevedo da Silva. Se trata de un inselberg de granito que se alza sobre la costa.

Fuente: $<$ http://averdadenomundo.blogspot.com/2012/09/misterios-e-curiosidad es-pedra-da-gavea.html $>$. 

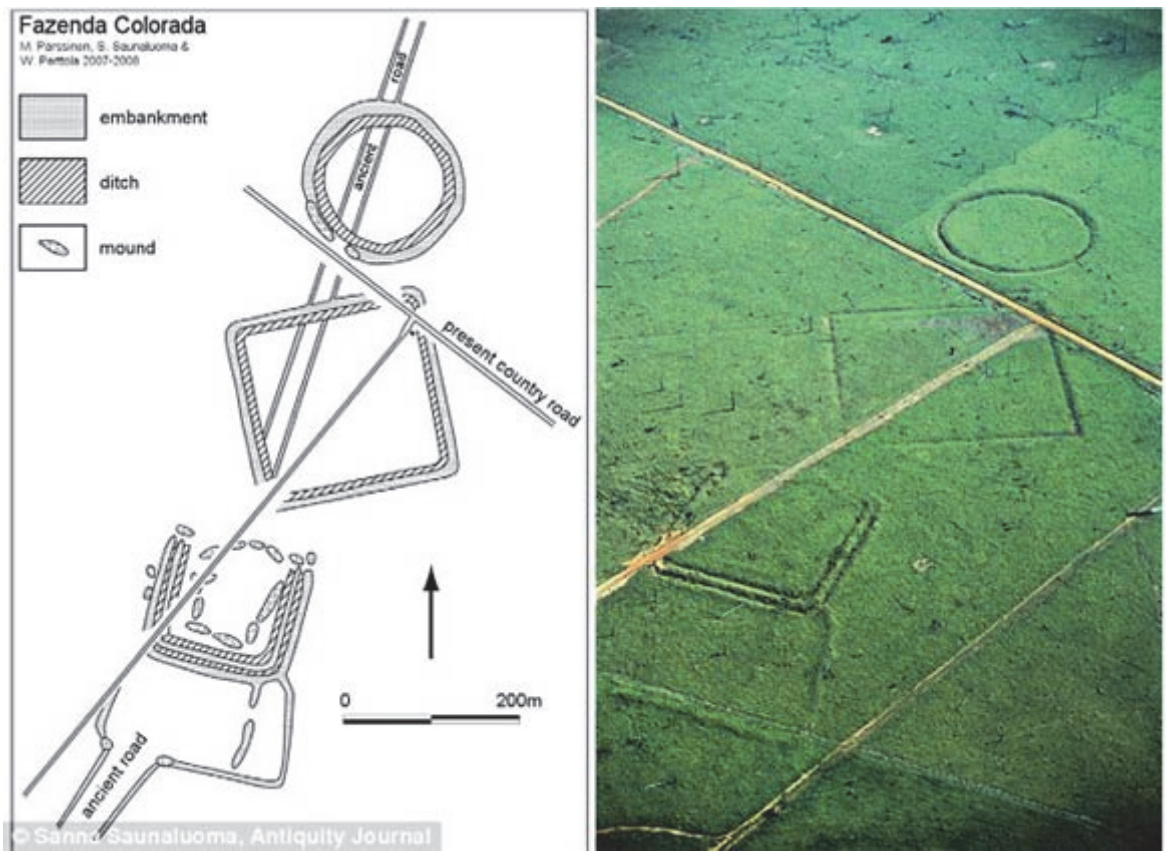

Figura 12. Imagen aérea y reconstrucción del sector "Fazenda Colorada" por M. Parssinen, S. Saunabuona y W. Oattola, 2007-2008.

Fuente: Edisson Caetano, Antiquity Journal, 2009.

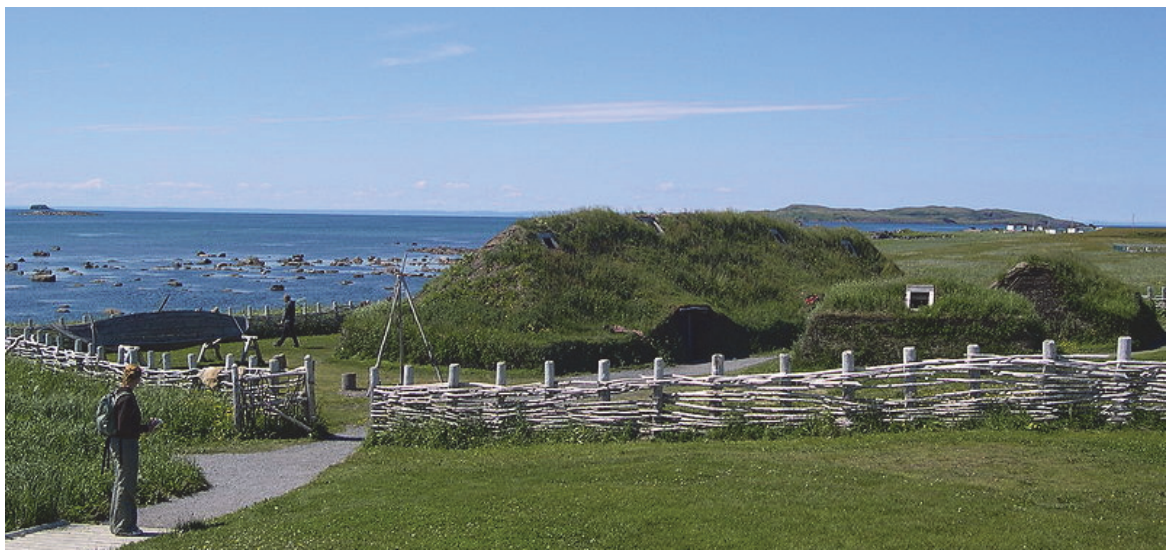

Figura 13. "L’Anse aux Meadows" Terranova, Canadá, asentamiento vikingo declarado patrimonio de la Humanidad por la UNESCO y donde se encontraron vestigios importantes de la presencia escandinava en Canadá.

Fuente: <http://es.wikipedia.org/wiki/Asentamientos_vikingos_en_Am $\% \mathrm{C} 3 \%$ A9rica>. 

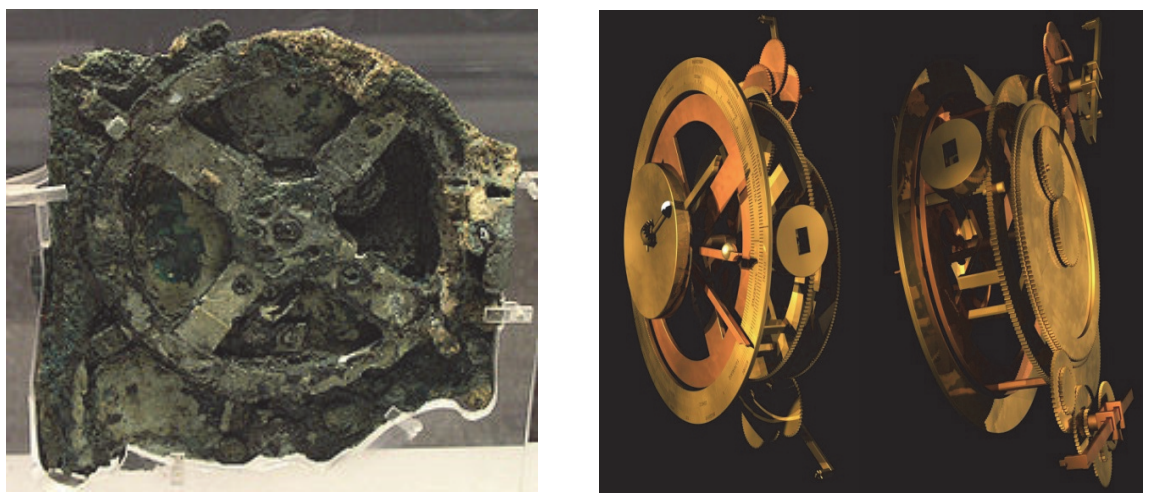

Figura 14. Mecanismo de anticitera, Grecia y reconstrucción por computadora.

Fuente: <es.wikipedia.org $>$.

\section{Conclusión}

Lo aquí expuesto pretende demostrar que la civilización humana ha sabido sobrevivir a los periodos críticos glaciares que atormentaron su pasado, creando condiciones difíciles de sobrellevar, pero que fueron capaces de conservar y transmitir los avances tecnológicos que se habían puesto a buen resguardo. Igualmente demostrar que durante los periodos interglaciares y en especial el inter Riss-Wurm es posible que se haya desarrollado una civilización avanzada, con conocimientos muy adelantados y que fueron transmitidos por las civilizaciones posteriores, egipcia, mesopotámica, griega, india y china. Algunos conocimientos fueron celosamente guardados por ellos porque eran avances tecnológicos desconocidos para la gran mayoría, como la pila de Babilonia, o bien el mecanismo de Anticitera rescatado del fondo del mar Egeo y datado de 65 a.C. se piensa que era un mecanismo astrológico o de navegación. La brújula que apunta hacia el Sur del emperador Chino Huang Di (2,698 y 2,598 a.C) sin hablar de los sistemas de canalizaciones de los incas o los conocimientos astronómicos mayas.

De lo que no cabe la menor duda es que nuestro planeta en los próximos 10,000 a 15,000 años sufrirá una nueva glaciación y pondrá nuevamente en jaque a nuestra civilización con toda su tecnología acumulada, particularmente aquella conservada en sistemas computacionales que dependen de la electricidad. Ello reducirá considerablemente a sus habitantes por el solo hecho de la escasez de alimentos. No olvidemos que entre el año 1800 y hoy el planeta ha pasado de 500 millones a 7,000 millones de habitantes y que el suelo agrícola y el agua son bienes limitados ¿Habrá logrado entonces, nuestra civilización, resguardar en profundos subterráneos todo el saber y la tecnología acumulada de nuestros días? ¿O bien alcanzar estrellas lejanas 
habitables donde perpetuar el conocimiento y el avance tecnológico, para poderlo retransmitir a aquellos descendientes que permanecieron en nuestro viejo planeta? ¿Cómo tal vez ya se hizo en el pasado?

\section{Bibliografia}

Ahn, J. and E. Brook, Atmospheric CO2 and Climate on Millennial Time Scales During the Last Glacial Period, Science 322, 2008.

Barcelli, S., "Entrevista a Yuri Leveratto, Suramérica desconocida", Hera Magazine, november, p. 28-35, 2009.

Bergoeing, J.P., “Modelado glaciar en la Cordillera de Talamanca”, Informe semestral, julio-diciembre, Instituto Geográfico Nacional, San José, Costa Rica, 1977.

, "Geomorfología de algunos sectores de Costa Rica basada en la fotointerpretación de imágenes del satélite Landsat en la banda espectral MSS7 (4 cartas color escala 1:500,000e)", Suplemento informe semestral, julio-diciembre vol. 28, pp. 3-15, Instituto Geográfico Nacional, San José, Costa Rica, 1982.

— Geomorfología de Costa Rica, Instituto Geográfico Nacional de Costa Rica pp. 460 (croquis, stereogramas, cartas, fotos), 1998.

—_, "La trangresión flandense", Revista Geográfica, núm. 144, pp. 229-239, Instituto Panamericano de Geografía e Historia, México, 2009.

Bergoeing, J.P. y Artavia, G., "Extensión glaciar y nival durante el riss/illinoiense y el wurm/wisconsiniano en las altas cumbres de Talamanca en el sector fronterizo Costa Rica-Panamá", Revista Geográfica, núm. 150, pp. 33-53, Instituto Panamericano de Geografía e Historia. México, 2012.

Bergoeing, J.P. y Protti, M., "Tectónica de placas y sismicidad en Costa Rica”, Revista Reflexiones, núm. 146, San José, Costa Rica, 2009

Bergoeing, J.P.; Arce, R.; Brenes, L.G. y Protti, R., Atlas Geomorfológico del Caribe de Costa Rica, escala 1:100,000, Editorial SIEDIN, Universidad de Costa Rica, 33 páginas a color, San José, Costa Rica, 2010.

Brook, E. and J., Severinghaus, "Correspondence: Methane and megafuana”, Nature Geosciences, vol. 4, pp. 271-272, 2011.

Cedeño, B. y López, A., "Ejes modificadores de las condiciones biofísicas de la cuenca del río Grande de Térraba", Ponencias EGAL XIII, UNA Suredes, Costa Rica, 2009.

Delort, R. and Walter F., Histoire de l'environnement européen, PUF, mai, 2001.

Dillehay, T.D.; Ramírez, C.; Pino, M.; Collins, M.B.; Rossen, J. and Pino-Navarro, J.D., "Monte Verde: seaweed, food, medicine, and the peopling of South America", Science, vol. 320, no. 5877, p. 784, 2008.

Gilbert, M.T.P.; Thomsen, P.F.; Binladen, J. and Willerslev, E., "DNA from PreClovis Human Coprolites in Oregon, North America”, Science, April 4, 2008.

Gordon, C., Before Columbus, Crown, New York, 1971. 
Jevrejeva, S.; Moore, J.C. and Grinsted, A., "Sea level projections to AD2500 with a new generation of climate change scenarios", Global and Planetary Change, Science Daily, October, 17, 2011.

Kirkpatrick, Sidney D., "An American Prophet”, Riverhead Books, 2000.

Milankovitch, M., Theorie Mathematique des Phenomenes Thermiques produits par la Radiation Solaire, Gauthier-Villars, Paris, 1920.

Pérez Crespo, V.A. et al., "La dieta y el habitat del mamut y los caballos del Pleistoceno tardio de El Cedral con base a isotopes estables ( $\delta 13 C, \delta 18 O)$ )", Revista Mexicana de Ciencias Geológicas, vol. 26, núm. 2, pp. 347-355, 2009.

Reiche, M., "Geoglifos prehistóricos en el Perú" (orig.: Prehistoric Ground Drawing in Peru); Offiz Indruck A.G., Stuttgart, 1955.

Rubio Sánchez, J. y Cuesta, J.M., Pasajes sobre el porvenir, profecías de H.P.B. para el III Milenio, Ed. Hiperbórea, España.

Shady Solis, R., Jonathan Haas y and Winifred Creamer. "Dating Caral, a Preceramic Site in the Supe Valley on the Central Coast of Peru", Science, vol. 292, no. 5517, pp. 723-726, 2001.

Silva Ramos de Azevedo, B., Inscripcões e tradiçoes da América prehistórica especialmente do Brasil, Rio de Janeiro, Imprensa Nacional, 1932.

Stephen S., Hall, "Nasca Lines: Spirits in the Sands", National Geographic, 2010. 